\title{
Evaluation of Agri-Environmental Measures in the Venice Lagoon Watershed. Nitrogen Budgets and Surplus Indicators
}

\author{
Marta Carpani ${ }^{1}$, Carlo Giupponi ${ }^{*}$, Patrizia Trevisiol ${ }^{1}$ \\ ${ }^{1}$ Dipartimento di Produzione Vegetale, Università di Milano \\ Via Celoria 2, 20133 Milano, Italy \\ ${ }^{2}$ Center for Environmental Economics and Management, Dipartimento di Scienze Economiche, \\ Università Ca’ Foscari di Venezia \\ S. Giobbe 873, 30121 Venezia, Italy
}

Received: 14 June 2008. Accepted: 25 September 2008.

\begin{abstract}
Summary
One of the main concerns of the environmental scientists and policy makers is related to the environmental compatibility of current agricultural systems and, in particular, to the losses of chemical fertilizers and manure in surface and ground-waters, as a consequence of run-off and leaching phenomena. In most cases European recent agrienvironmental schemes envisaged specific measures for the reduction of fertilizer rates and the control of manure applications, in order to limit the releases of nutrients in surface and ground-waters. Substantial financial resources are invested in those measures and therefore the issue raises interest in monitoring and evaluating their effectiveness. Nutrient balance indicators are often used for quantitative assessment of the effectiveness of the measures in limiting the environmental impact of farming activities. $\mathrm{N}$-surplus is one of the most commonly used indicators. The paper refers the results of a research project aimed at assessing the outcomes of agri-environmental measures implemented in the Venice Lagoon Watershed with an approach based upon the gross nitrogen balance, called "Nboxes".

The results of applying the Nboxes procedure to a sample of 550 farms set are presented, evidencing the expectations of greater effectiveness in terms of nitrogen surplus reduction from the measure C.5.1.3a and C.5.1.3b (low input farming and buffer strips). Measures supporting improved irrigation systems, controlled drainage and more rational livestock nutritional programmes and technologies, showed instead only limited potential for tangible contributions to the reduction of nitrogen surplus in cultivated soils.
\end{abstract}

Key-words: nitrogen balance, surplus indicator, agri-environmental measures, assessment, policy support.

\section{Introduction}

Over the years the growing awareness of citizens and environmental organisations about water resources raised the demand for cleaner rivers and lakes, groundwater and coastal beaches pushed the European Commission to insert water protection as a priority of policy and legislative agendas. Water quality has been a crucial environmental issue for the European Union for decades, since, for instance the Community Water Policy Ministerial Seminar of Frankfurt in 1988, which brought the European
Community to ask for a series of measures. Initially, proposed measures concerned with water for human consumptions and human activities (i.e. bathing waters, fish and shellfish waters), with the adoption of several directives, such as the Urban Waste Water Treatment Directive (91/271/EEC) and of the Nitrate Directive (1991/676/EEC), and culminating with the Water Framework Directive (WFD, 2000/60/EC) and its related directives, which provided a comprehensive legislative reference and policy tool, to introduce in the whole European Union a more global, holistic, approach to water policy

\footnotetext{
* Corresponding Author: Tel.: +39 041 2349126; Fax: +39 041 2349176. E-mail address: cgiupponi@unive.it
} 
aimed at the very ambitious objective of reaching a "good status" of European water bodies, by 2015 .

One of the main concerns of both the scientists and the policy makers related to the issue of reaching the ambitious objectives of the WFD is related to the environmental compatibility of current agricultural systems and, in particular, to the use of chemical fertilizers and manure in crop production and their losses in surface and ground-waters, as a consequence of run-off and leaching phenomena.

In many developed countries, the shift towards specialised and intensive farming systems determined evident unbalances between the input of nutrients in feed and fertilizers, with respect to the outputs in agricultural productions, thus significantly contributing to diffuse nutrient losses in leaching and runoff water, polluting ground and surface water resources (Heathwaite, 2003).

In parallel to the development and implementation of environmental policies targeting the preservation and enhancement of water quality, great efforts have been devoted to the re-orientation of agricultural systems towards more sustainable ones, these being matters of the Common Agricultural Policy (CAP).

The CAP is a complex and continuously evolving legislation, in which the primary objectives of increasing agricultural productivity, stabilising markets, and ensuring a fair standard of living for the agricultural community, have been implemented through a long sequence of regulations. Since the late 1980's, and in particular with the Mac Sharry Reform of the CAP in 1992, European regulations have focused more and more on environment, by introducing a specific set of agri-environmental measures. Worth to be cited at this regard is the recent Reg. n. 1698/2005 (EC, 2005), in which the principles and rules of Rural Development Plans for the period 2007-2013 are provided along four axes, of which, the second is about "Improving the environment and the countryside". According to the regulation, Member Sates and regions design and apply agri-environmental measures providing financial support for those farming practices helping to protect the environment and maintain the countryside, going beyond the baseline level of so-called "good farming practices" (GFP), and the minimum level of environmental standards ("cross-compliance").
Farmers can thus opt for signing commitments (voluntary agreements) for a 5-year minimum period, to adopt specific environmentally-friendly techniques indicated in the local agrienvironmental measures, and receive in return payments that compensate for additional costs and loss of incomes. In most cases European recent agri-environmental schemes envisaged specific measures for the reduction of the use of fertilizers and control of manure application, in order to limit the releases of nutrients in surface and ground-waters.

Given the amount of financial resources invested in those measures, the issue raises interest in monitoring and evaluating their effectiveness. Indicators are needed for providing specific and quantitative assessment of the effectiveness of the measures, but the complexity of the phenomena to be analysed - spatio-temporal nutrient balances are affected by varying environments and farmers' practices - makes their identification to be a challenging issue.

Many different methods and operational tools are available, for carrying out agri-environmental assessments in order to support policy and decision making. An analysis of the recent literature focused on the different scales and approaches clearly shows that simulation models are commonly used at detailed scales while indicators are preferred in broader geographical contexts (Giupponi and Carpani, 2006). Various modelling approaches provide descriptions of the inputs, outputs and processes of the agro-ecosystems under study, and allow for simulations of present, past or future states of the system, according to previously defined policy scenarios, thus providing support to, respectively, in itinere, ex post and ex ante assessment. In turn models can provide quantitative values for significant assessment indicators.

The effects of nutrient losses (nitrogen and phosphorous in particular) on ground and surface water quality are approached by the scientific literature at various levels. Nutrient balances are commonly considered as powerful tools for the analysis of environmental impacts and later for the optimisation of nutrient use efficiency and controlling nutrient losses. In particular, the nitrogen balance can be defined as the physical difference (surplus/deficit) between nitrogen input into and output from an agricultural system per hectare of agricultural land, 
over a year (OECD, 2001). A positive difference indicates a surplus accumulated in the system or lost outside it, a negative one, indicates a deficit that would deplete the system stock.

In general, nutrient balances indicators (Oborn et al., 2003) can be calculated with data available at different scales (from field to nation) and results are easy to communicate to farmers and policy makers. Most commonly nutrient balances are elaborated at the "farm gate" or at the "soil surface" level to calculate nutrient surpluses as a proxy of risk potential over various nutrient loss pathways (van Beek et al., 2003). A soil surface balance lists all ingoing and outgoing flows at the field level and is orientated towards an assessment of the $\mathrm{N}$ input into the soil. Available $\mathrm{N}$ in manure and mineral fertilizers represent two important inputs while $\mathrm{N}$ removed by crop products is a major output. In the farm gate balance, instead, manure (unless imported to the farm) and crop products (unless exported to other farms) are considered as internal flows and are hence not included. Fertilizers, feed imports and agricultural produce exports are the main balance terms in this case.

If the surplus is to be used to express total $\mathrm{N}$ loss to the environment, gaseous losses should be included within the calculation. If, however, the surplus is intended as an indicator only for $\mathrm{N}$ leaching risk, all gaseous losses and temporary net accumulation of inputs (e.g. in systems that have recently resumed manuring) should be considered as outputs (Schroder et al., 2003). Changes in soil organic $\mathrm{N}$ should also be considered over the long-term.

Gross nutrient balances are suggested as monitoring and evaluation indicators by the Handbook on common monitoring and evaluation framework, provided by EU-DG-Agri in September 2006 ${ }^{1}$. In particular Annex 3 selects the "Changes in gross nutrient balance (GNB)" as the measurement to be carried out in order to quantify the Impact indicator "Improvement in water quality", and the surpluses of nitrogen and phosphorus as measurements for the baseline indicator "Water quality: Gross Nutrient Balances". According to the Handbook, the "GNB indicates potential nutrient losses to the water bodies likely to be detrimental for the quality of water" and from GNB, "an estimate of the potential surplus of nitrogen [and phos- phorus] on agricultural land" can be derived from "the amounts of mineral fertilizer applied, organic fertilizer production, nitrogen fixed in the soil, atmospheric deposition of nitrogen compounds, seeds and planting material, and amounts of harvested crops and forage".

Examples of the use of nutrient balances can be found in Parris (1998) or in the Dutch Mineral Accounting System (MINAS) that was introduced in 1998 to reduce nitrogen and phosphorus losses through a farm gate balance sheet (Oenema et al., 1998; Ondersteijn et al., 2002; Schroder et al., 2003). Whole-farm nutrient balances have played an important role in the assessment of environmental performances of agricultural activities and in some cases have also been implemented in legislation, such as the case of nitrogen management in the Netherlands (Schroder et al., 2003).

Balance calculations - in particular those at the farm gate level - are primarily intended to provide information on the environmental impact of a farm expressed on an areal basis. Results are also used for comparison between farms and to evaluate a farmer's 'environmental performance', or as a screening model to provide estimation of significant indicators, such as the N-surplus, for the assessment of the effectiveness of agri-environmental measures.

When gross balances are used for orienting farmers' choices, they serve as tools to identify the best combinations of inputs and outputs in such a way that the annual surplus does not exceed certain thresholds, or a permitted value, which could be specified as a function of farm typology and soil type.

The nutrient surplus as determined by a balance of inputs and outputs represents an indicator providing an intermediate assessment between the goal-oriented indicators, such as "nitrate concentration in groundwater" and the means-oriented indicators, such as " $\mathrm{N}$ input via manure" or "livestock density" (Jansen et al., 1999; Van Noordwijk, 2001).

Whole-farm $\mathrm{N}$ balances are considered relatively responsive and moderately goal-oriented indicators for nitrate losses to groundwater, thus

See http://ec.europa.eu/agriculture/rurdev/eval/guidance/document_en.pdf and related annexes. 
representing a possible solution for the assessment of the impacts of measures, by comparing ex post vs. ex ante balances, as proposed by the EU Dg-Agri Handbook cited above. Nevertheless, nutrient surpluses and related indices should be interpreted with caution when used as indicators for the environmental impact of agriculture, management quality and resource utilisation, and to orient farmers choices. At this regard, it should be remembered that, in contrast to the past when recycling of by-products (e.g. crop residues, manure) was an ordinary farm activity, these byproducts are now often considered 'wastes' ((Schiere et al., 2002; Van Noordwijk, 2001). Such strategies may improve the NUE (Nitrogen Use Efficiency) of individual farms, but at the expense of the average surplus of the population of farms, when livestock farmers prefer to use highly digestible concentrates rather than crop residues, and arable farmers use more mineral fertilizers rather than manure. Consequently, manure may be applied at rates exceeding crop demand at the livestock farm and crop residues may be left in the fields on the arable farm.

Currently, most scientists and authorities focus on surpluses per unit area (S) as an indicator for environmental impact, but it would be also worth to evaluate farming systems in terms of their surplus per unit output $(\mathrm{S} / \mathrm{O})$ and their utilisation of resources other than $\mathrm{N}$.

The present paper refers preliminary and overall results of a research project aimed at assessing the outcomes of agri-environmental measures implemented in the Venice Lagoon Watershed. It represents a side effort of the work reported in Giupponi et al. (2008) in this issue, in which, the assessment techniques based upon expert knowledge elicitation are here paralleled by the evaluation of measures' performance with an approach based upon the gross nitrogen balance, called "Nboxes".

In the following section we present material and methods, starting with the description of the screening model developed for the accounting of the nitrogen balance at the soil surface and farm gate levels, ad a presentation of the set of indicators provided by Nboxes as outputs. In the same section we introduce the case study, the specific agri-environmental measures examined, and the data set of farms used to test the evaluation procedure.
In the third section the results of applying the Nboxes procedure to the farm data set are presented, and some conclusions are driven in the last section of the paper.

\section{Materials and methods}

\subsection{Nboxes}

The nitrogen balance implemented in Nboxes was developed upon the scheme of nitrogen balance presented in Schröder et al. (2003), thus processing data collected with farm surveys to produce a farm gate nitrogen balance, described by a set of input and output indicators. Such nitrogen balance permits to highlight the fluctuation of nitrogen loads generated at farm level through the 'nitrogen surplus' indicator calculated as the difference between inputs (mineral and organic fertilizers, purchased products, atmospheric deposition, etc.) and outputs (animal and crop yield sold, and losses).

Nboxes differs from the approach proposed by Schröder et al. (2003) first of all because the flows between different compartments are not expressed in terms of conversion coefficients, but they are represented by stock-and-flow relationships, with stocks determined by absolute values describing production processes as described in the farm survey, and flows regulated by rate variables listed in reference tables derived from the literature, thus permitting also a dynamic calculation of balances over time. Moreover, Nboxes calculates the farm gate balance from the combination of soil surface balances of the various fields of the farm, thus requiring a rather intensive collection of data through an ad hoc farm survey and pre-existing data bases. By means of this evolved approach towards nitrogen balance calculations, some of the limitations typical of the farm gate balances could be overcome, thanks in particular to the possibility of disaggregating the contributions of the various farm production units and evidencing their compensatory effects.

Both the results of the farm surveys and preexisting data bases about the characteristics of the study area (soils and climate) and of the production processes (characteristics of the cultivated crops, machineries utilised, fertilizers, etc.) were preliminarily stored in the on-line da- 


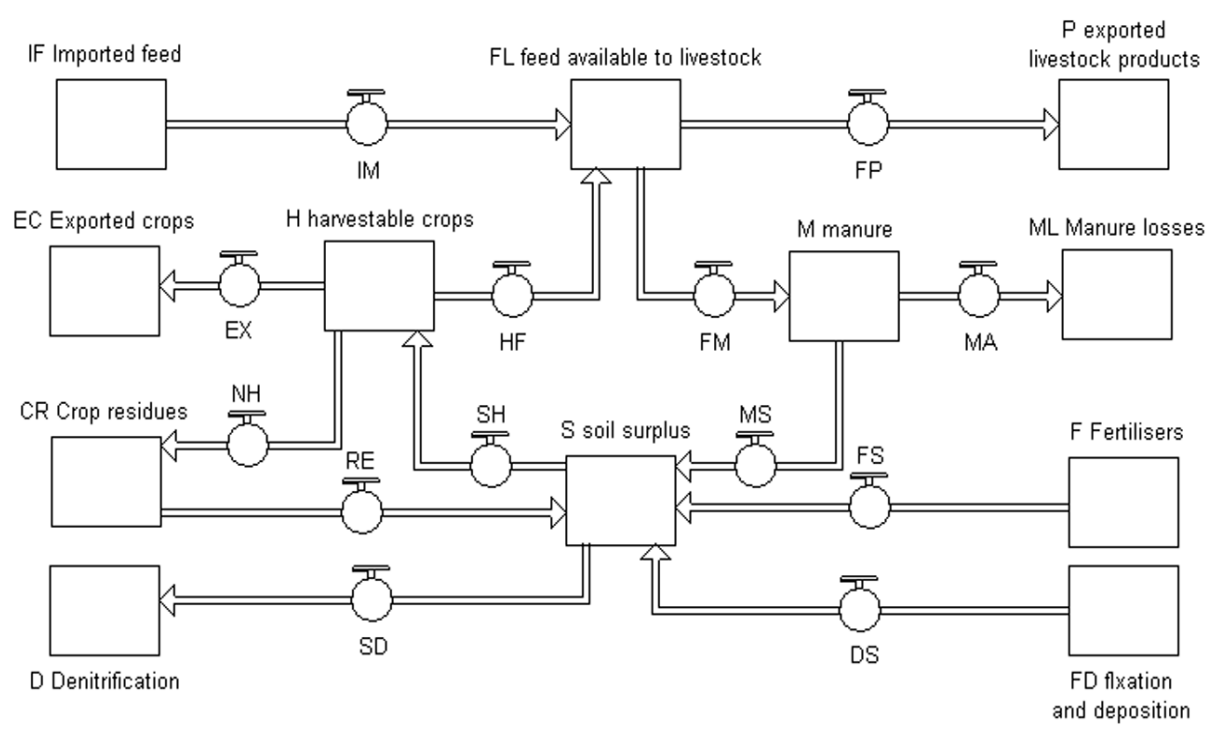

Figure 1. Flow chart of methodology to calculate nitrogen balance at farm and field scale.

ta base of the AGeNDA Project ${ }^{2}$ (Giupponi, 2002). The Nboxes software thus operates as a post-processor of AGeNDA that elaborates farm data by extracting all the relevant information for nitrogen balance calculation and providing as outputs a series of indicator values (e.g. surplus per hectare).

Information stored in the AGeNDA database are highly disaggregated, providing Nboxes with information allocated to homogeneous cultivation units called Farm Land Units (FLU), i.e. a field-by-field description of crop rotations and their cultivation techniques. Similarly, the various livestock productions and the fate of manure are described, when present in the farm.

Data extracted from AGeNDA are elaborated by the Nboxes stock-and-flow model of nitrogen balance, as depicted in Figure 1. The nitrogen stocks considered are:

- Imported feed (IF)

- Feed available to livestock (FL)

- Exported livestock products (P)

- Harvested crops $(\mathrm{H})$

- Exported crops (EC)

- Crop residues (CR)

- Manure (M)

- Manure losses during housing, stoking and application (ML)

- Mineral fertilizers applied to crops (F)

- Nitrogen atmospheric deposition and fixation (FD)

- Denitrification (D)

- Soil surplus (S).
Regarding the flows connecting the various stocks of the nitrogen balance, $\mathrm{SH}$ expresses the ability of crops to convert nitrogen in the soil stock into harvestable crop nitrogen; HF rates the conversion of harvestable crop nitrogen $\mathrm{N}$ into nitrogen available in animal feed, while FM expresses the flow of nitrogen from animal rearing to manure; FP describes the ability to convert feed-N into nitrogen contents of animal productions (milk, eggs, etc.); MS represents the effective transfer of manure-N to soil-N, by limiting the gaseous losses from stables, manure storages and manure applications (MA) ${ }^{3}$. Influxes in soil stocks are also represented by FS (fertilizers), nitrogen content of residues (RE), and nitrogen fixation and deposition (DS). A detailed presentation of the nitrogen balance algorithms is reported in Annex 1.

\footnotetext{
2 The project AGeNDA provided a web based software for storing and manipulating farm data related to crops, soils, animals, buildings, machinery, irrigation water, chemical and manure inputs, designed for supporting farming systems' assessments before (ex ante) and after (ex post) the implementation of the agri-enviornmental measures in the Venice Lagoon Watershed. It collects data of 550 farms surveyed by officials of the regional environmental protection agency, as an obligation included in the agri-environmental schemes. AGeNDA provided also the link between the information provided by farmers and the available geographical data bases (soils, climate, cultivation techniques, etc.).

${ }^{3}$ Naming of rate variables is kept consistent with the balance presented in Schröder et al. (2003).
} 
Various indicators are calculated by Nboxes and six of them are of particular interest for the present application, with the aim of assessing the effectiveness of agri-environmental measures of the case study:

- Soil surplus $\left(\mathrm{S} ; \mathrm{kg}_{\mathrm{N}} \mathrm{ha}^{-1}\right)$

- Surplus per unit agricultural output (S/O; $\mathrm{kg}_{\mathrm{N}} \mathrm{ha}^{-1} / \mathrm{kg}_{\mathrm{N}} \mathrm{ha}^{-1}$ )

- Agricultural output per unit of input $(\mathrm{O} / \mathrm{I}$; $\mathrm{kg}_{\mathrm{N}} \mathrm{ha}^{-1} / \mathrm{kg}_{\mathrm{N}} \mathrm{ha}^{-1}$ )

- Delta soil surplus as a consequence of the Agri-Environmental Scheme (AES) overall $\left(\Delta S ; \mathrm{kg}_{\mathrm{N}} \mathrm{ha}^{-1}\right)$

- Delta soil surplus provided by low-input cultivation systems $\left(\Delta \mathrm{Sc} ; \mathrm{kg}_{\mathrm{N}} \mathrm{ha}^{-1}\right)$

- Delta soil surplus provided by buffer strip plantation $\left(\Delta \mathrm{Sb} ; \mathrm{kg}_{\mathrm{N}} \mathrm{ha}^{-1}\right)$

- Delta soil surplus provided by higher efficiency irrigation systems $\left(\Delta \mathrm{Si} ; \mathrm{kg}_{\mathrm{N}} \mathrm{ha}^{-1}\right)$

- Delta soil surplus provided by controlled drainage $\left(\Delta \mathrm{Sd} ; \mathrm{kg}_{\mathrm{N}} \mathrm{ha}^{-1}\right)$.

As previously stated, the stock named "Soil surplus" is utilised as a proxi of potential environmental impact of agricultural activities, based on the consideration that this stock can be depleted through water losses as a consequence of both runoff and leaching phenomena. Therefore, the effectiveness of measures is calculated as the difference between the balances after and before the implementation of the measures, through the "Delta soil surplus" indicators, calculated as multi-annual averages of crop rotations.

The assumption that a relationships exists between the nitrogen available in the soil and its losses in water bodies, is rather coarse in the light of the knowledge of the phenomena that regulate nutrient losses from cultivated fields, but it was deem acceptable, for the purposes of this work, since it is the indicator suggested by the common monitoring and evaluation framework of the EU Dg-Agri. Nevertheless, care should be placed especially avoiding to interpret the "Delta" indicators as absolute estimation of the benefits, in particular when referring to farms that have recently adopted low-input management, like in the present case.

\subsection{The Venice Lagoon Watershed case study}

The Venice Lagoon Watershed (VLW; approximately $1,850 \mathrm{~km}^{2}$ ) is the portion of the alluvial plain of the Veneto Region (north-eastern Italy), characterised by an almost entirely flat morphology, a very complex hydrography, with short spring rivers and artificial canals discharging into the Venice Lagoon.

Regarding agricultural land use (approximately two thirds of the VLW surface), the most important crop is maize (see Tab. 1), with significant portions of the area covered by winter wheat, sugar beet, vineyards, and meadows. According to census data, about 210,000 bovines and 130,000 swine are reared in the VLW, with intensive livestock production systems and scarcely integrated with crop production.

According to the outcomes of the participatory work reported in Giupponi et al. (2008) the present work focused on four measures within the broader menu of schemes financed by the Veneto Regional Government since 2002 (DGR, 2002), with the aim of contributing to the assessment of the effectiveness of the agrienvironmental policy, all together with parallel efforts carried out with different methodological approaches.

Relevant for the present work is the fact that the Regional Administration included in the agri-environmental schemes the activity for the collection of data needed for the current application, within the above mentioned project AGeNDA. Farmers were thus receiving specific compensations for their availability to provide the information required and participated in the related farm agri-environmental audit activities.

The four measures selected for the present assessment are:

- Measure C.5.1.3a, "Low-input agriculture",

Table 1. Agricultural land use of the VLW.

\begin{tabular}{lr}
\hline Crop & ha \\
\hline Winter wheat and other small grains & 11249 \\
Maize (grain) & 92393 \\
Maize (forage) & 5626 \\
Sugar beet & 9294 \\
Soybean & 22228 \\
Rice & 89 \\
Other & 2256 \\
Market gardens & 4868 \\
Protected crops & 630 \\
Lucerne & 4967 \\
Other forage crops & 474 \\
Vineyard & 9874 \\
Fruit trees & 3484 \\
Meadows & 8879 \\
Set aside & 5749 \\
\hline
\end{tabular}


including a mandatory programme of farm extension service, limitations to the rotational choices, imposing longer crop rotations (5 years), reduction of fertilizers rates by $50 \%$ as compared to those of the Code of Good Agricultural Practices (CGAP), and irrigation scheduling based upon a simplified soil water balance.

- Measure C5.1.3b, "Buffer strip plantation or maintenance and set aside": a 10-year set aside programme, or a 5-year obligation to convert cultivated land to buffer strips ( 5 to $30 \mathrm{~m}$ wide), to be maintained or planted ex novo, all together with the obligation to adopt the provisions of the CGAP.

- Measure C5.1.3c "Irrigation management and controlled drainage", providing financial support for the adoption of higher efficiency irrigation systems (sprinklers instead than gravitational systems), or for the implantations of controlled tile drainage systems.

- Measure C5.1.4 "Management of livestock effluents and improved rearing structures and equipments", providing financial support for implementing new farm structures for the treatment of liquid manures, new nutritional programmes and feeding technologies, machinery improvement for soil application of effluents and advanced machineries for soil tillage.

Table 2 reports the number of farms that adopted the various schemes proposed by the regional administration and Figure 2 shows their geographical distribution. Worth to be mentioned is the fact that the number of farms adopting the various measures was limited by the financial provisions allocated by the administration to the various AES's. Subsequent calls were opened to allow for further participation of farmers to the programme and the allocation

Table 2. Number of farms adopting the measures provided by the Agri-Environmental Schemes (AESs) for the VLW.

\begin{tabular}{ll}
\hline AES & Number of farms adopting the measure \\
\hline C.5.1.3a & Low-input agriculture: 391 farms \\
\hline C5.1.3b & $\begin{array}{l}\text { Buffer strips: } 397 \text { farms }(712 \mathrm{~km}) \text {; Set aside: } \\
16 \text { farms }\end{array}$ \\
\hline C5.1.3c & Drainage: 31 farms; Irrigation: 208 farms \\
\hline C5.1.4 & $\begin{array}{l}\text { New technologies for livestock rearing plants } \\
\text { and effluent management: } 373 \text { farms }\end{array}$ \\
\hline
\end{tabular}

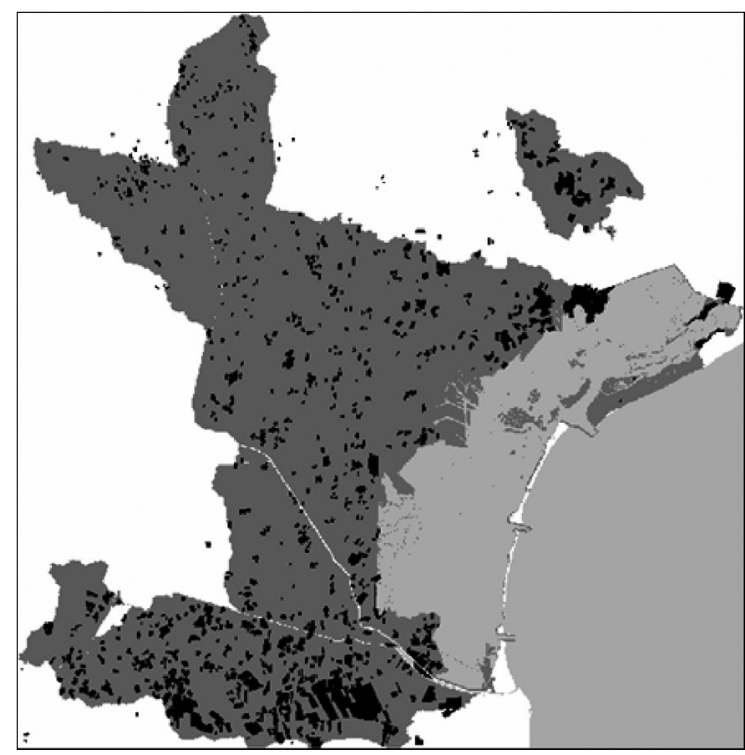

Figure 2. Map of the Venice Lagoon Watershed (pale grey), with the boundaries of the farms participating to the AES's.

of funds was guided by the success, in terms of applications submitted, for the different measures. Therefore, the number of farms joining the schemes can be considered directly proportional to the success of the various measures proposed, while, on the other hand, the availability of funds could not match farmers' requests, thus limiting the overall adoption of the measures. In total 550 farms were involved in the AGeNDA project and thus provided the data for the present work. Some of them adopted more than one measure, thus totalling 730 records in the AGeNDA database.

An ad hoc procedure was developed for the extraction of data required as input by the Nboxes model from the AGeNDA data base. That procedure included the selection of required information from 27 different tables out of the 66 utilised by the AGeNDA data base, associated to the same farm record (e.g. machinery operations, commercial fertilizers and their dosage, crop characteristics, etc.) and data pre-processing for allowing detailed nitrogen budget computation at the soil surface and later at the farm gate (e.g. allocation of information to the pertinent farm units, called Farm Landscape Unit and quantification of the multi-temporal values to be included in the nitrogen budget). Data extracted from the online 
AGeNDA data base were stored locally in a single MS-Excel ${ }^{\circledR}$ spreadsheet. $^{-}$

Data analysis in Nboxes is possible on a farm by farm basis, by selecting the farm code from a catalogue, or in a single run, by processing the whole database and producing a new spreadsheet as output file.

In both cases, the procedure applies three parallel calculation of the nitrogen budget at the farm gate, resulting from the combination of soil surface balances per FLU:

1. Scenario 0: budget before the adoption of agri-environmental measure(s) (ex ante).

2. Scenario 1: ex post budget after the adoption of those measures having directs effects on the nitrogen balance:

- low-input farming;

- set aside;

- buffer strip effects in terms of nitrogen uptake by planted trees and of reduced overall applications;

- irrigation (with reduction of fertilizer inputs);

- livestock (with changes in effluent management: stocking, treatment, or soil application systems).

3. Scenario 2: ex post budget, after the adoption of those measures having indirect or un-
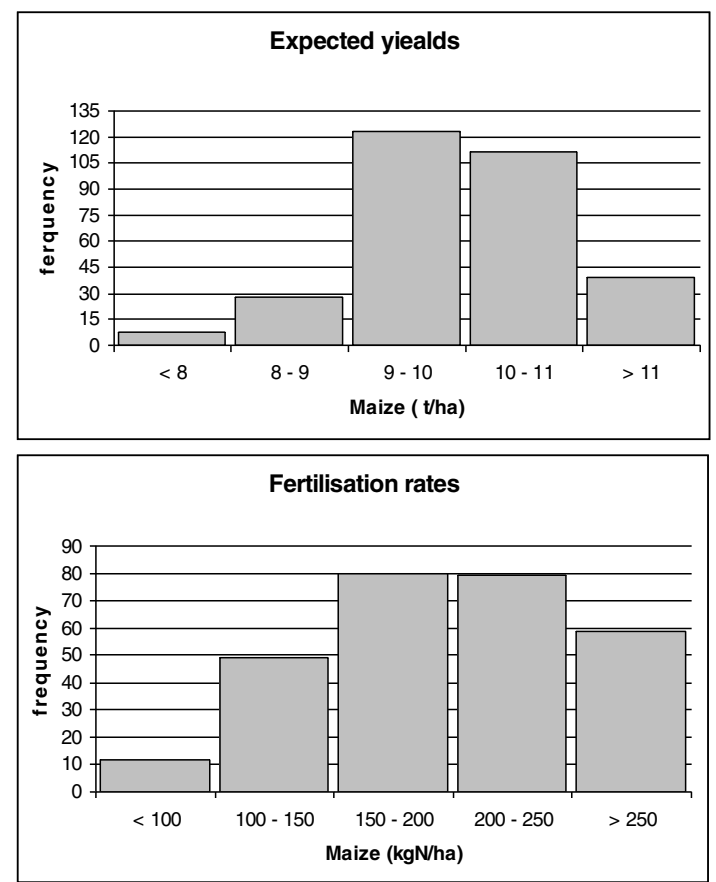

certain effects on the nitrogen balance:

- irrigation (with variation of the water volumes, without reduction of fertilizers' rates);

- set aside with phyto-remediation plants;

- buffer strips effects in terms of denitrification;

- controlled drainage in terms of reduced the water losses and denitrification;

- livestock (with change in the animal feed and/or soil tillage).

The Delta surplus indicator is thus calculated from the surplus calculated, for Scenario 1 minus Scenario 0 (benefits from direct changes in the nutrient balance), and Scenario 2 minus Scenario 0 (additional benefit deriving from the combined indirect effects on water and nitrogen balances).

\section{Results}

\subsection{Agricultural land use}

The access to the AGeNDA data base provided a great wealth of information about the cultivation systems of the VLW, but at the same time raised the issue of the quality of data acquired through interviews with farmers. Figure 3 shows the frequency distribution of fertiliza-
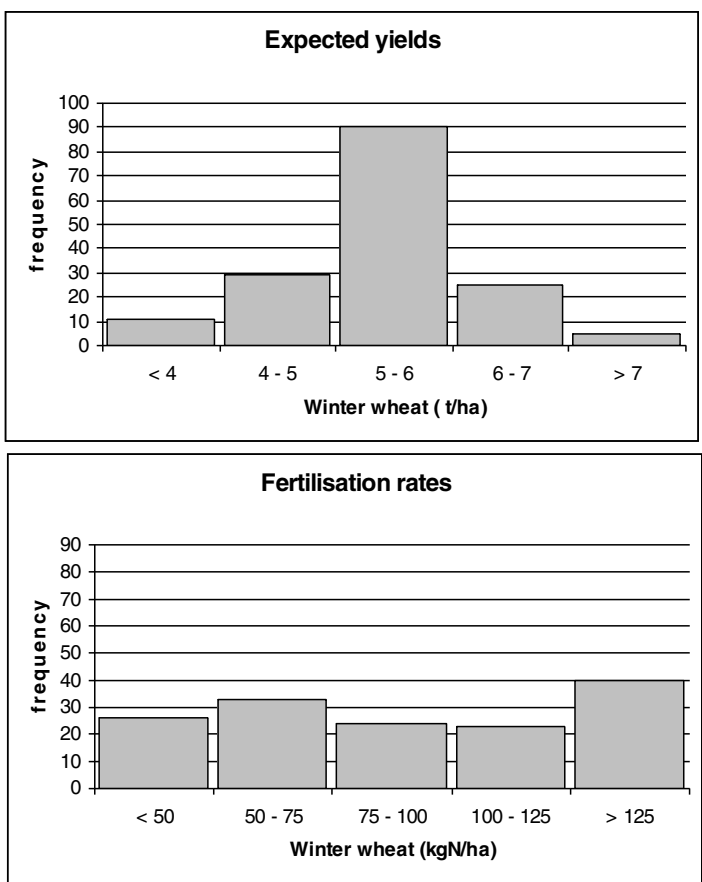

Figure 3. Frequency distribution of yields and fertilization rates in ex ante situation related to the most important crops in the VLW (Winter Wheat and Maize). 
tions and yields in the ex ante situation for the two most important crops of the area: winter wheat and maize. It is clear that chemical fertilizer rates below $150 \mathrm{~kg} \mathrm{ha}^{-1}$ of nitrogen for maize are not realistic. There are cases of very low rates in case of important applications of manure, but checks of input data executed randomly on the data base confirmed the existence of problems typical of data collected with farmers' interviews: a limited capability of small farmers to provide adequate records of the cultivation practices, problems in the conversion between metric units and local ones (e.g. regarding the unitary cultivated surface area, the "field", varying in size in different areas of the VLW), recording and transcription errors, etc.

Given the availability of several hundreds farm records, a preliminary screening out of evidently inconsistent records was performed, while further verifications of doubtful questionnaire was left to the possibility of returning to the farms within the activities related to the auditing service to be carried out by the Regional Environmental Protection Agency. As a result a subset of farm data was obtained with average values recorded in the farm survey consistent with rates suggested by extension services and local technicians, and thus considered adequate for the exploratory purposes of the present work (Table 3 show average values of input and outputs and reference values for the most important crops of the VLW).

Table 3 shows that the fertilization rates imposed by the measure for low input agriculture are in general below the estimated uptake of nitrogen for the most important crops, thus showing evidence of likely reduced yields that should be expected in the coming years in the farms which adopted the measure. In the short term residual positive effects could be provided by nutrient stocks available in soils, but very accurate fertilization techniques will be needed to increase the effectiveness of fertilizers.
The comparison between the current allocation of land to the various crops and the allocation after having implemented the rotational limits imposed by the measure C.5.1.3a shows a remarkable effect in terms of increased acreage of leguminous crops, from 16 to more than $20 \%$ of the UAA (Utilised Agricultural Area). Similarly winter wheat and other small grains are expected to raise from 15.3 to $17.7 \%$, while maize currently quite often cultivate as a monoculture in the area should decrease from 41.5 to $36.7 \%$. Such a more balanced and diversified land use can be considered as a first positive result of the implementation of the measures.

\subsection{Nitrogen surplus}

The primary objective of environmental policies for the preservation of water quality in the Venice Lagoon and its watershed is the abatement of nitrogen concentrations in water discharged into the lagoon. Therefore, nitrogen surpluses of the cultivated soils can be considered only as good proxy indicator of the contribution of the agricultural sector to water pollution. Similarly, the variation of surpluses determined by the implementation of agri-environmental measures is a good relative indicator for the assessment of the effectiveness of those policies.

On purpose in the present work we do not present any calculation of the overall benefit in terms of reduced surplus of the measures, because the data base requires further consolidation, but also because the main interest of this preliminary application of the Nboxes tool is devoted to the analysis of the potentials of the different measures in relative terms.

An overall preliminary picture of the expected effectiveness of the measure can be derived from the histograms reported in Figure 4.

Grey histograms show the estimated variations of the farm surpluses as a consequence of the implementation of the whole package of

Table 3. Average nitrogen inputs and outputs and reference limits for the VLW.

\begin{tabular}{|c|c|c|c|c|}
\hline & Maize & W. wheat & S. beet & Soybean \\
\hline Average yields according to the questionnaires $\left(\mathrm{t} \mathrm{ha}^{-1}\right)$ & 10.5 & 5.6 & 63.2 & 4.2 \\
\hline Average nitrogen fertilization according to the questionnaires $\left(\mathrm{kgN} \mathrm{ha}^{-1}\right)$ & 218 & 101 & 98 & 17 \\
\hline Average expected plant uptakes $\left(\mathrm{kgN} \mathrm{ha}^{-1}\right)$ & 147 & 112 & 126.4 & 210 \\
\hline Fertilization rates according to the CGAP $\left(\mathrm{kgN} \mathrm{ha}^{-1}\right)$ & 280 & 180 & 150 & 20 \\
\hline Fertilization rates according to measure C.5.1.3a $\left(\mathrm{kgN} \mathrm{ha}^{-1}\right)$ & 140 & 90 & 75 & 0 \\
\hline
\end{tabular}




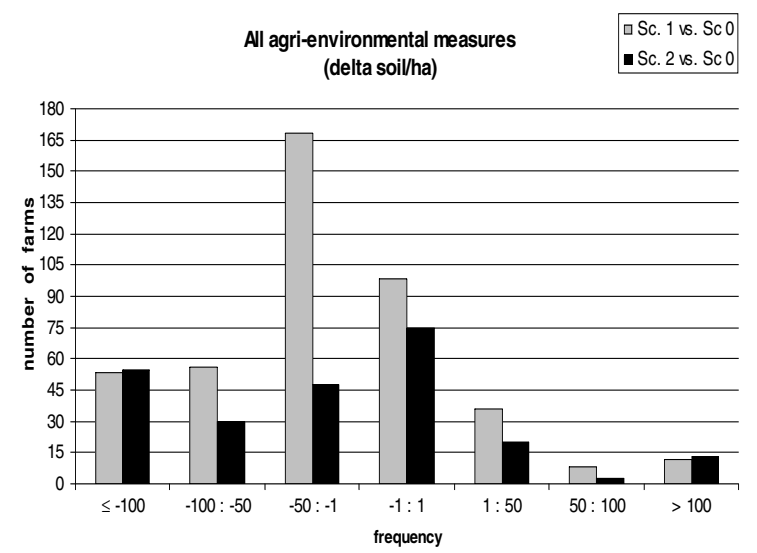

Figure 4. Variations of nitrogen surplus per hectare as a consequence of the application of agri-environmental measures, according to the Nboxes budgets: direct effects (Scenario 1 vs. Scenario 0) and indirect or uncertain effects (Scenario 2 vs. Scenario 0).

measures in the farms assessed by means of Agenda-Nboxes according to Scenario 1, compared with the situation ex ante (Scen. 0). Black bars in the histogram show the variation of surplus in all the farms adopting the specific measures considered by Scenario 2 (see above): Scen. 2 vs. Scen. 0. The graphs clearly show that evident positive effects (i.e. negative values of Delta surplus per hectare) are calculated for the vast majority of farms, when comparing Scen.1 with Scen.0, while the benefits of those measures that are not directly affecting inputs and outputs of the nitrogen balance (besides being more uncertain) are much less evident, with many cases of possible negative effects (i.e. increases of nitrogen surpluses).

According to the results of the calculation of surpluses with Nboxes, the overall reduction of the nitrogen surplus in the farms joining the AES's is estimated to be around 1100 t. This is in theory a remarkable contribution to the reduction of diffuse pollution of agricultural origin, since the target of the Lagoon Master Plan (Veneto, 2000) is to reduce the nitrogen loads from a total of 9,000 $\mathrm{t}$ discharged in the average hydrologic year to a maximum of $3,000 \mathrm{t}$, with an estimated contribution from agricultural and animal farming sources of about $65 \%$. Nevertheless, it should be remembered that the variations of surpluses at the farms gates are only indirectly related to the final discharges of nitrogen in the lagoon. The latter require the im- plementation of complex distributed hydrologic and chemical models, whose application is possible only in situations of very good data availability.

Very interesting is the analysis of the estimated benefits of the measure identified as the most promising in terms of effectiveness by the experts involved in the participatory workshop reported in Giupponi et al. (2008). The graph reported in Figure 5 clearly shows that, when considering only the measure C.5.1.3a (low-input agriculture) the cases with limited or negligible improvements in the nitrogen budget tend to disappear, with reductions of the surplus most frequently in the classes between 10 and $50 \mathrm{~kg} \mathrm{ha}^{-1}$ or between 50 and $100 \mathrm{~kg} \mathrm{ha}^{-1}$. Still, around 30 cases show opposite effects which should be carefully assessed case by case.

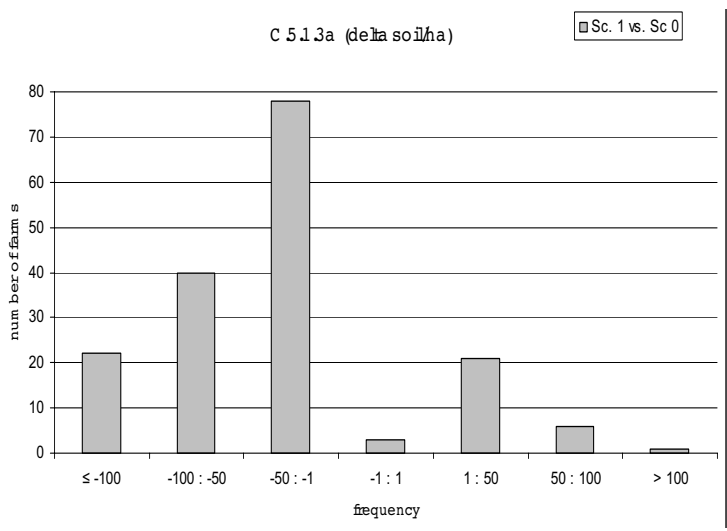

Figure 5. Variations of nitrogen surplus per hectare as a consequence of the application of measure C.5.1.3a (low-input farming), according to the Nboxes budgets (Scenario 1 vs. Scenario 0).

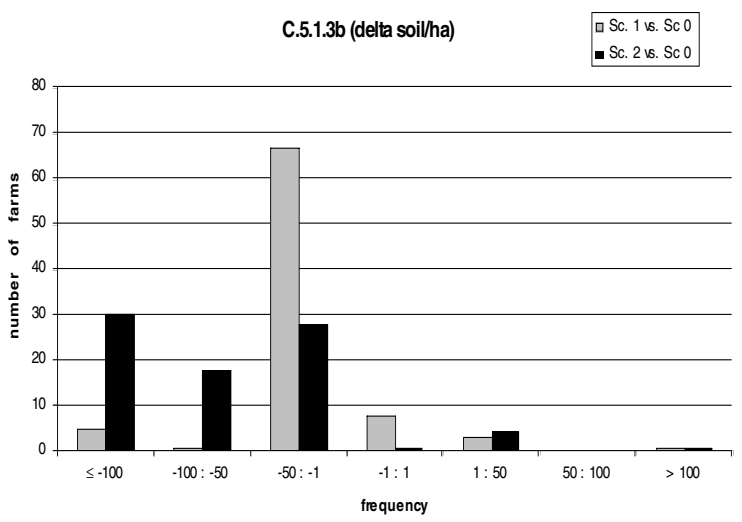

Figure 6. Variations of nitrogen surpluses per hectare as a consequence of the application of measure C.5.1.3b (buffer strips), according to the Nboxes budgets. 
Similarly, and again in accordance with the outcomes of the participatory expert workshop, the plantation or maintenance of buffer strips (measure C.5.1.3.b) show general positive effects, but when considering only direct contributions to the nitrogen balance (i.e. the reduction of inputs at the farm level and the uptake by the non-fertilized vegetation of the buffer) most frequently the reduction of surplus is between 1 and $50 \mathrm{~kg}$ ha ${ }^{-1}$ with many cases of negligible effects (e.g. large farms with limited surfaces converted into buffer strips). More evident are the effects when considering the potential positive effects of denitrification as reported in Figure 6 (black bars showing potential additional benefits).

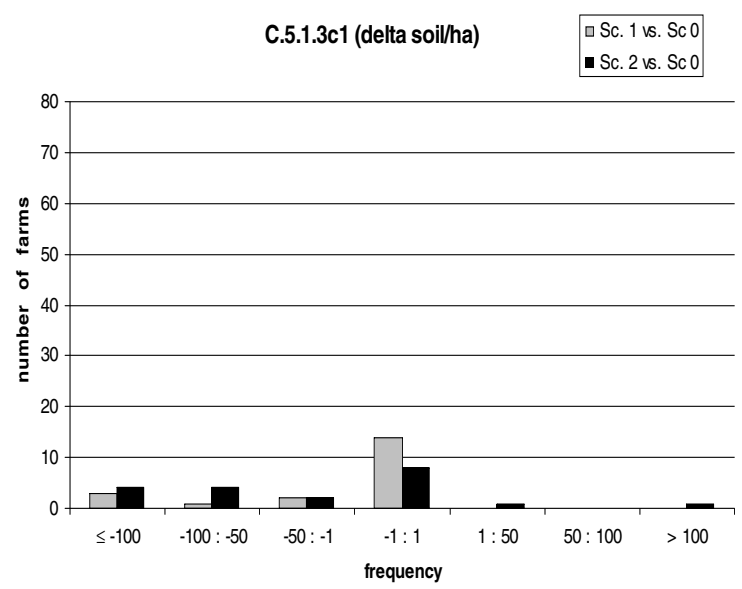

Figure 7. Variations of nitrogen surpluses per hectare as a consequence of the application of measure C.5.1.3c1 (irrigation management), according to the Nboxes budgets.

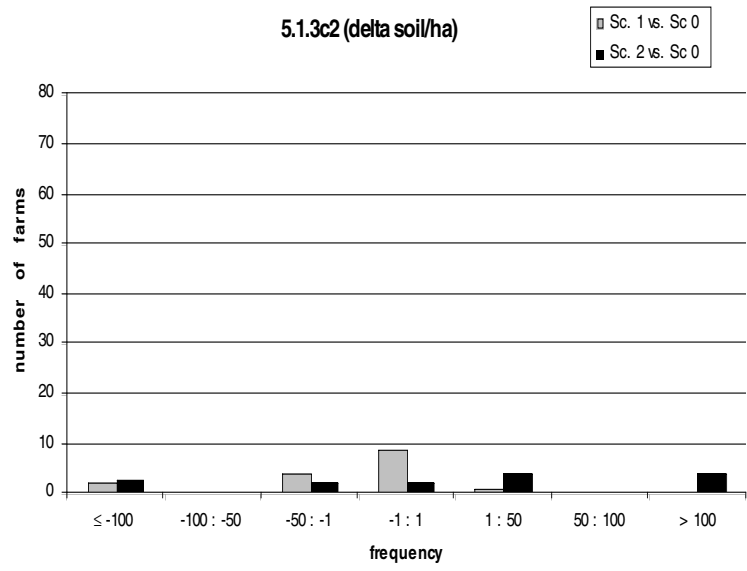

Figure 8. Variations of nitrogen surpluses per hectare as a consequence of the application of measure C.5.1.c2 (controlled drainage), according to the Nboxes budgets.
Histograms reported in Figures 7-8 clearly show first of all that, compared to the measure C.5.1.3a (low-input agriculture, Figure 5) the farms that chose the C.5.1.3c measure (irrigation management and controlled drainage) are few.

Figure 7 in particular shows that in general only marginal effects could be attributed to the irrigation management measure (C.5.1.3.c1) since the most frequent class shows a delta soil between -1 and $1 \mathrm{~kg} \mathrm{ha}^{-1}$, with the remaining farms evenly distributed throughout all the classes of surplus reduction. The other measure considered is the controlled drainage (C.5.1.3.c2; Figure 8) and similarly the largest group of farms show a delta soil between -1 and $1 \mathrm{~kg} \mathrm{ha}^{-1}$ for Scenario 1 . The other farms show a measure effectiveness with just one exception. On the contrary in the Scenario 2 the higher number of farms ( 8 farms) show a negative effect of the measure since are grouped in the classes of surplus between 1 and $50 \mathrm{~kg} \mathrm{ha}^{-1}$ and over $100 \mathrm{~kg} \mathrm{ha}^{-1}$.

Similarly, few farms adopting the C.5.1.4 measure (livestock management) were included in the AGeNDA data base. Those adopting measure C.5.1.401 and C.5.1.404 (improved nutritional programmes and feeding technologies) are examined in Figure 9. Results show again limited evidences of positive effects of these measure on the surplus of nitrogen. Once more the most frequent case of Delta surplus is between -1 and $1 \mathrm{~kg} \mathrm{ha}^{-1}$.

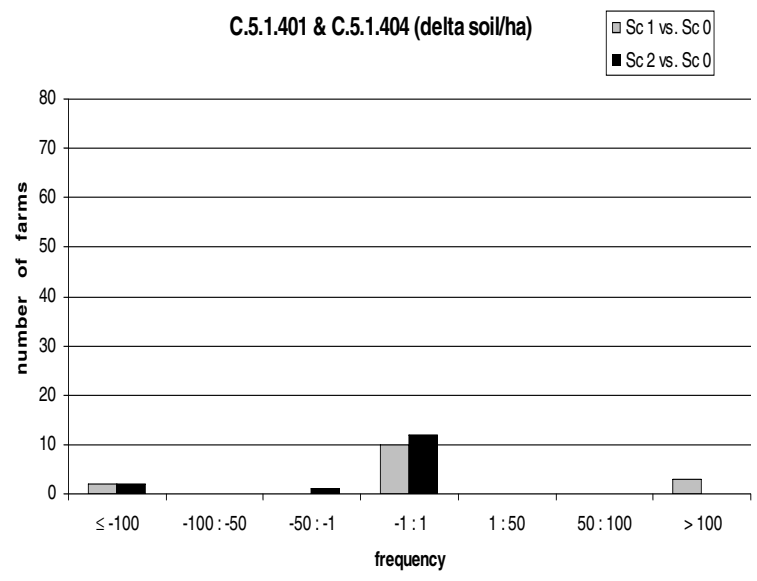

Figure 9. Variations of nitrogen surpluses per hectare as a consequence of the application of both measure C.5.1.401 and C.5.1.404 (new nutritional programmes and feeding technologies), according to the Nboxes budgets. 


\section{Discussion and conclusions}

Gross nutrient budgets and the nitrogen surplus indicator are recommended by several international institutions such as the OECD and the EU as effective means for assessing the impacts of agricultural activities on the quality of water resources. They are suggested in particular for the assessment of the effectiveness of agri-environmental measures. The scientific literature is broad at this regard and many drawbacks have been identified so far, first of al the excessive simplification of nitrogen balances and their only indirect relationships with the releases of nutrients from cultivated fields and discharges in water bodies.

The present work has developed an algorithm and a tool aimed at overcoming some of the limitations cited above, in particular for what concerns the simplifications of farm gate balances.

The preliminary results presented above, demonstrated that the approach proposed has reached an operational stage in assessing the effectiveness of a diversified set of measures implemented in the VLW, in accordance with the official evaluation criteria. The Nboxes tool allowed for clearly identifying differentiated effectiveness levels of the various measures, thus providing non doubtful indications in terms of consolidating and reorienting future agri-environmental policies.

At this regard the measures aimed at the implementation of lower input agricultural systems, with changes of land use in terms of crop rotations and plantation buffer strip present not only undoubtful effects on nutrient balances, but also evident simplification in the control phase.

The following aspects have to be carefully considered in view of further application of Nboxes in assessment of AESs (after the necessary efforts for consolidating the databases):

\section{Data quality}

1) doubts were raised about the information provided by farmers about farming systems before the implementation of the measures;

2) problems were found in the data base due to errors in the phases of data registration on paper during the interviews and of data transcription in the on-line data base.

There is an evident trade-off between the possible use of - relatively reliable and stable and easy to acquire - "reference" values (e.g. regarding fertilization rates) that could be acquired in the official statistics or from local experts, and "punctual" data acquired with farmers' interviews, that are less reliable, but much closer to the diversity of situations that characterises farming practices farm-by-farm. In order to control the data quality problem, interviewers should be carefully trained, data collected should be accurately screened and data verification should be allowed through second round interviews. The number of interviews should be high enough to allow discarding those farm records that do not pass the quality control procedure, which should include checks of inconsistent data also at the stage of nitrogen balance calculation.

\section{Relationship between nitrogen balance indicators and environmental targets}

The objectives of the regional environmental plan for the preservation of the Venice Lagoon ecosystem are expressed in terms of tons of nitrogen discharged. Farm gate balances provide only a very indirect and approximated estimation of the possible benefits of the agri-environmental measures. Delta surpluses are indicators describing the generation of nitrogen loads, which do not consider the fate of nutrients from the cultivated fields down to the lagoon. In order to have an estimation of the benefits in terms of discharges an accurate and calibrated distributed hydrologic and chemical simulation model would be required. But the effort in terms of data needs and research effort would be dramatically increased.

In the present case the concordance of the overall results with the outcomes of participatory modelling techniques with the involvement of reference experts of the area support the potential positive contribution of the Nboxes approach applied in parallel with other methodologies.

Future efforts should be targeted towards the identification of a set of representative farms to be used for extrapolations to the level of the whole VLW. This could be done by integrating the AGeNDA-Nboxes data bases with the available GIS data layers (e.g. farm cadastre).

Worth to explore is the progressive integration of scientific evidences in the farm survey 
data base. For instance response curves acquired in controlled field experiment could be integrated in the system, in parallel to the information about fertilizer rates and yields provided by farmers.

As planned in the regional regulation providing resources for the implementation of the AES's, auditing activities could be implemented with the farmers involved in data collection and the results of the Nboxes software could be used for discussions with farmers about possible alternative low impact practices. This could be done also in connection with the activities related to the implementation of the Nitrate Directive and the Water Framework Directive.

\section{Acknowledgements}

The authors gratefully acknowledge the financial support of ARPAV (Veneto Region Environmental Protection Agency), with the technical assistance of P. Giandon and G. Barban.

\section{References}

DGR Decreto della Giunta Regionale 2002. Piano per la prevenzione dell'inquinamento delle acque del Bacino sversante nella Laguna di Venezia. Interventi nel settore agricolo e zootecnico. Bando di apertura termini per la presentazione delle domande. Bollettino Ufficiale della Regione Veneto, Suppl. al. n. 88:109.

EC European Commission, 2005. COUNCIL REGULATION No 1698/2005 of 20 September 2005 on support for rural development by the European Agricultural Fund for Rural Development (EAFRD). Official Journal of the European Communities, L:40.

Giupponi C. 2002. AGeNDA: a project for developing a new tool for sustainable farm management. In: Poppe K.J., Povellato A. (eds.): European farmers and the growing of data, INEA, 43-53.

Giupponi C., Carpani M. 2006. Recent Developments in Indicators and Models for Agri-environmental Assessment. Italian Journal of Agronomy, 1:647-664.

Giupponi C., Fassio A., Sgobbi A. 2008. Evaluation of agri-environmental measures in the Venice Lagoon Watershed. Expert knowledge elicitation and multicriteria analysis. Italian Journal of Agronomy, 3:147165.
Heathwaite A.L. 2003. Making process-based knowledge useable at the operational level: a framework for modelling diffuse pollution from agricultural land. Environmental Modelling \& Software, 18:753-760.

Jansen D.M., Buijze S.T., Boogaard H.L. 1999. Ex-ante assessment of costs for reducing nitrate leaching from agriculture-dominated regions. Environmental Modelling and Software, 14:549-565.

Oborn I., Edwards A.C., Witter E., Oenema O., Ivarsson K., Withers P.J.A., Nilsson S.I., Richert Stinzing A. 2003. Element balances as a tool for sustainable nutrient management: a critical appraisal of their merits and limitations within an agronomic and environmental context. European Journal of Agronomy, 20:211-225.

OECD Organisation for Economic Co-operation and Development 2001. Environmental Indicators for Agriculture: Methods and Results. OECD, Paris.

Oenema O., Boers P.C.M., van Eerdt M.M., Fraters B., van der Meer H.G., Roest C.W.J., Schroder J.J., Willems W.J. 1998. Leaching of nitrate from agriculture to groundwater: the effect of policies and measures in the Netherlands. Environmental Pollution, 102:471-478.

Ondersteijn C.J.M., Beldman A.C.G., Daatselaar C.H.G., Giesen G.W.J., Huirne R.B.M. 2002. The Dutch Mineral Accounting System and the European Nitrate Directive: implications for $\mathrm{N}$ and $\mathrm{P}$ management and farm performance. Agriculture, Ecosystems \& Environment, 92:283-296.

Schiere J.B., Ibrahim M.N.M., van Keulen H. 2002. The role of livestock for sustainability in mixed farming: criteria and scenario studies under varying resource allocation. Agriculture, Ecosystems \& Environment, 90:139-153.

Schroder J.J., Aarts H.F.M., ten Berge H.F.M., van Keulen H., Neeteson J.J. 2003. An evaluation of whole-farm nitrogen balances and related indices for efficient nitrogen use. European Journal of Agronomy, 20:33-44.

van Beek C.L., Brouwer L., Oenema O. 2003. The use of farmgate balances and soil surface balances as estimator for nitrogen leaching to surface water. Nutrient Cycling in Agroecosystems, 67:233-244.

Van Noordwijk M. 2001. Plant nutrition: Its role in sustainability of simple and complex agro-ecosystems. Plant Nutrition, 2-3.

Veneto Regione 2000. Piano Direttore 2000. Decreto del Consiglio Regionale n. 24. 


\section{Annex 1. Nitrogen budget calculations implemented in Nboxes (see Figure 1)}

\section{H: Nitrogen in havestable crops}

$\mathrm{H}$ is represented in Nboxes as a stock of nitrogen deriving from the ability of crops to uptake nitrogen available in the soil stock S. H is calculated for every FLU (Farm Land Unit) from the annual rotational average of the uptakes of the crops cutivated in the rotation $\left(\mathrm{CU}_{\mathrm{R}}\right)$, multiplied by the surface area (ha) of the FLU (UAA FLU $)$

$$
\mathrm{H}(\mathrm{kg} \mathrm{N})=\sum\left(\mathrm{CU}_{\mathrm{R}} \cdot \mathrm{UAA}_{\mathrm{FLU}}\right)
$$

$\mathrm{CU}_{\mathrm{R}}$ is given by the average of the unitary amount of nitrogen per type of harvestable products, $\mathrm{CU}_{\mathrm{i}}$ (Crop Uptake):

$$
\mathrm{CU}_{\mathrm{i}}\left(\mathrm{kg} \mathrm{N} \mathrm{ha}^{-1}\right)=\mathrm{EY}_{\mathrm{i}} \cdot \mathrm{TU}_{\mathrm{i}}
$$

where:

$\mathrm{EY}_{\mathrm{i}}=$ expecetd yield per crop i $\left(\mathrm{t} \mathrm{ha} \mathrm{a}^{-1}\right)$

$\mathrm{TU}_{\mathrm{i}}=$ total nitrogen uptake per crop i per unit of yield $\left(\mathrm{kg} \mathrm{N} \mathrm{t}^{-1}\right)$, deducted of the quota returned to the soil with residues (CR).

As outputs, the stock $\mathrm{H}$ has: Nitrogen in Crop Residues (CR), Nitrogen in Exported Crops (EC), and Nitrogen in Feed available to livestock (FL).

\section{CR: Nitrogen in Crop Residues}

The nitrogen in crop residues is expressed by the rate variable NH (see Figure 1), expressing the quota of crop nitrogen returning to the soil stock (S) through the decomposition of residues (RE) incorporated in the soil.

$$
\begin{aligned}
\mathrm{CR}(\mathrm{kg} \mathrm{N}) & =[\mathrm{EY} \cdot(1-\mathrm{HH}) \cdot \mathrm{RH} \cdot \mathrm{RC} \cdot \\
& (1 / \mathrm{CN})] \cdot \mathrm{UAA}_{\mathrm{FLU}}
\end{aligned}
$$

where:

$\mathrm{HH}=$ humidty ratio of harvested crop (fraction of 1)

$\mathrm{RH}=$ Residues / harvest ratio $\left(\mathrm{t} \mathrm{t}^{-1}\right)$

$\mathrm{RC}=$ Carbon content of residues $(\%)$

$\mathrm{CN}=$ Carbon / Nitrogen ratio of residues (fraction of 1).

CR is calculated only for those crops whose residues are returned to soil.

\section{EC: Nitrogen in exported crop products}

Nitrogen in exported crop products (EC; $\mathrm{kg} \mathrm{N}$ ) is calculated like $\mathrm{H}$, but including only the nitrogen contents of crops that are exported, i.e. sold by the farmer.
FL: Nitrogen in feed available to livestock

The amount of nitrogen available to livestock in the proteins is rated through the conversion of both harvestable crop nitrogen $\mathrm{H}$ and the Imported Feed (IF) through the specifics rates assessing nitrogen available in animal feed (HF, IM respectively), according to the unitary amount of nitrogen in the protein of the daily ration per head, per animal category (UF):

$$
\text { UF }\left(\mathrm{kg} \mathrm{head}^{-1} \mathrm{~d}^{-1}\right)=\sum[\mathrm{FQ} \cdot \mathrm{DM} \cdot(\mathrm{RP} / 6.25)]
$$

$\mathrm{FQ}=$ foodstuff quantity used per livestock typology $\left(\mathrm{kg} \mathrm{d}^{-1}\right)$

$\mathrm{DM}=$ dry matter $(\%)$

$\mathrm{RP}=$ raw protein content $(\%$ on $\mathrm{DM})$.

Inputs to FL (i.e. FI) are calculated by summing up the contents of nitrogen in the various feeds of the diet, by considering the average length of breeding period (BP), including both internal $(\mathrm{H})$ and external (IF) sources.

$$
\mathrm{FI}(\mathrm{kg})=\sum\left[\mathrm{HN}_{\mathrm{j}} \cdot \sum(\mathrm{UF} \cdot \mathrm{BP} \cdot 30)\right]
$$

$\mathrm{HN}_{\mathrm{j}}=$ number of heads per animal category $\mathrm{BP}=$ breeeding period (months).

Two types of outputs from the FL stocks are considered: the nitrogen content in exported livestock products $(\mathrm{P})$, expressed by the rate FP, and the $\mathrm{N}$ content of the effluents produced by reared animals (M), expressed by the rate FM.

\section{P: Nitrogen in exported livestock products}

$$
\mathrm{P}(\mathrm{kg})=\sum\left[\mathrm{HN}_{\mathrm{j}} \cdot \sum(\mathrm{UF} \cdot \mathrm{FP} \cdot \mathrm{BP} \cdot 30)\right]
$$

where:

$\mathrm{FP}=$ coefficient expressing the residual nitrogen proportion of $\mathrm{N}$ excreta per unit of $\mathrm{N}$ in feeds, per animal category.

\section{M: Nitrogen in livestock waste}

The amount of nitrogen in livestock wastes is calculated acording to:

$$
\mathrm{M}(\mathrm{kg})=\sum\left[\mathrm{HN}_{\mathrm{j}} \cdot \sum(\mathrm{MC} \cdot \mathrm{BP} \cdot 30)\right]
$$

where:

MC $\left(\mathrm{kg} \mathrm{head}^{-1} \mathrm{~d}^{-1}\right)=$ average daily amount of nitrogen in the effluents per animal category.

Nitrogen content of the effluents is later applied to soil according to the fertilization rates defined in the crop cultivation practices. The original amount of $\mathrm{N}$ is reduced by considering the losses during stocking, treatement (if any) and soil application (ML). In case 
not all the nitrogen available for soil application is used according to the fertilization rates defined in crop cultivation itineraries, the remaining surplus of $\mathrm{N}$ is added to the farm surplus and highlighted by a specific indicator named LWU (Live Weight Units).

\section{$M L$ : Nitrogen losses from manure}

As previously stated three possible forms of losses are considered and summed up to obtain the net amount of $\mathrm{N}$ from livestock wastes available in the soil, MS.

$$
\mathrm{MS}(\mathrm{kg})=\mathrm{LE}-\mathrm{SL}-\mathrm{AL}
$$

where:

$\mathrm{LE}=$ nitrogen content in livestock excreta SL $(\mathrm{kg})=\mathrm{LE} \cdot \mathrm{SLC}=$ nitrogen losses during stocking and treatment according to the coefficient SLC (\%), specific of the technology implemented in the farm (not considered for pasture)

$\mathrm{AL}(\mathrm{kg})=(\mathrm{LE}-\mathrm{SL}) \cdot(\mathrm{L}<7 \mathrm{~d}+\mathrm{L}>7 \mathrm{~d})=$ nitrogen losses at the soil application, depending on two coefficients $\mathrm{L}<7 \mathrm{~d}$ and $\mathrm{L}>7 \mathrm{~d}(\%)$ expressing the percentages of losses within and after 7 day from application, respectively, which depends on the machinery utilized for manure spreading or incorporation.

\section{F: Nitrogen in fertilizer inputs}

Records of commercial fertilizers rates per crops (FS) are derived from crop cultivation practices.

The F stock summed up with the net nitrogen contents of the manures (MS), when they are applied, on a FLU by FLU basis. Annual averages are obtained by considering the sequence of crops in the FLU rotation.

\section{FD: Nitrogen fixation and atmospheric deposition} Nitrogen deriving from symbiontic $\mathrm{N}$-fixation is not accounted in the budget, because it is considered equal to the uptake of those crops, while atmospheric deposition is added to the budget, according to an averaged value for the whole VLW.

\section{D: Nitrogen lost through deitrification}

A denitrification component is added only in Scenario 2 calculation in case of measures supporting the implementation of buffer strip plantation or maintenance, controlled drainage, or set aside with phytoremediation plants.

Calculation of $N$ surplus indicators

- $\mathrm{N}$ surplus in soil (per farm or per hectare): $\mathrm{SS}=\mathrm{F}+(\mathrm{M}-\mathrm{ML})+\mathrm{FD}-\mathrm{H}+\mathrm{CR}$

- Delta N surplus in soil (per farm or per hectare) $\mathrm{DSS}=\mathrm{SS}_{x}-\mathrm{SS}_{0}$

where $x$ indicate analyzed scenario, and thus $\mathrm{SS}_{0}$ is the nitrogen surplus in the ex ante situation.

- Delta buffer strips (per farm or per hectare):

where:

$$
\mathrm{DBS}=\mathrm{FT} \cdot \mathrm{SS}_{0}
$$

FT is the denitrification coefficient that depends on drainage situation of the field and the ratio between the extent of the buffer strip plantation and the the surface area of the farm

- Delta phytoremediation (per farm or per hectare):

where:

$$
\mathrm{DP}=\mathrm{FD} \cdot \mathrm{SS}_{0}
$$

FD is the denitrification coefficient that depends on the ratio between the extent of the area converted to phytoremediation and the the surface area of the farm

- Delta irrigation (per farm or per hectare):

where:

$$
\mathrm{DI}=\mathrm{IR} \cdot \mathrm{SS}_{0} \cdot\left[\mathrm{IV}_{0}-\mathrm{IV}_{2}\right] / \mathrm{IV}_{0}
$$

IR is an empiric coefficient to determine soil nitrogen balance variations due to irrigation volume (IV) changes in scenario 0 and 2.

- Delta drainage (per farm or per hectare):

where:

$$
\mathrm{DD}=\mathrm{DR} \cdot \mathrm{SS}_{0}
$$

DR is an empiric coefficient to determine soil nitrogen balance variations due to drainage type (controlled drainage vs. other drainage types). 
